\title{
The Effect of Transabdominal Amnioinfusion on Perinatal Outcomes in Preterm Premature Rupture of Membranes
}

\author{
${ }^{1}$ Saba Fatima, ${ }^{2}$ Nasira Tasnim, ${ }^{3}$ Ghazala Mahmud
}

\begin{abstract}
Objective: To evaluate the role of transabdominal amnioinfusion in improving the latency period and perinatal outcomes of pregnancies complicated by preterm premature rupture of membranes (PPROM).
\end{abstract}

Materials and methods: A randomized controlled trial was carried out at $\mathrm{MCH}$ Centre, Unit I, PIMS, Islamabad, from Jan 2008 to Dec 2008. Sixty women with singleton pregnancies between 28 and 32 completed weeks of gestation, complicated with PPROM was randomly allocated into two groups viz transabdominal amnioinfusion (amnioinfusion group) and expectant management (control group), within 24 hours of admission.

Results: The demographic characteristics were comparable in both the groups. Amnioinfusion group showed significant improvement in PPROM to delivery interval $(18.47 \pm 6.699 \mathrm{vs}$ $8.93 \pm 4.741$ days; $p=0.001)$, neonatal birth weight $(p=0.019)$ and Apgar scores at 1 and 5 minutes $(p=0.007$ for 1 minute and $p=0.012$ for 5 minutes). There was less frequency of respiratory distress syndrome $(p=0.032)$, neonatal sepsis $(p=0.020)$ and neonatal jaundice $(p=0.002)$ in the amnioinfusion group. Fewer neonates were admitted to NICU $(p=0.010)$ and higher survival rate was found in amnioinfusion group $(p=0.023)$.

Conclusion: The treatment with transabdominal amnioinfusion in pregnancies complicated with PPROM resulted in significant prolongation of pregnancy and better neonatal outcomes as compared to women who were managed with traditional expectant management.

Keywords: Perterm premature rupture of membranes, Transabdominal amnioinfusion, Respiratory distress syndrome.

How to cite this article: Fatima S, Tasnim N, Mahmud G. The Effect of Transabdominal Amnioinfusion on Perinatal Outcomes in Preterm Premature Rupture of Membranes. J South Asian Feder Obst Gynae 2014;6(1):28-32.

Source of support: Nil

Conflict of interest: None

${ }^{1}$ Postgraduate Resident, ${ }^{2}$ Associate Professor, ${ }^{3}$ Professor and Head

1-3 Department of Obstetrics and Gynecology, Maternal and Child Health Centre, Pakistan Institute of Medical Sciences Islamabad, Pakistan

Corresponding Author: Saba Fatima, Postgraduate Resident Department of Obstetrics and Gynecology, Maternal and Child Health Centre, Pakistan Institute of Medical Sciences Islamabad, Pakistan, Phone: 0092-3235139962, e-mail: spady_20@hotmail.com

\section{INTRODUCTION}

Preterm premature rupture of membranes (PPROM), account for $45 \%$ of preterm deliveries and $20 \%$ of neonatal mortalities, the incidence being much higher in developing countries. ${ }^{1}$ The reason for preterm intervention in these cases is oligohydramnios. The management of preterm premature rupture of membranes has traditionally focused on conservative management, i.e. antibiotics, corticosteroids and bed rest, all of which were considered useful tools for prolongation of pregnancy, especially in areas where neonatal intensive care was not available. ${ }^{2}$

Transabdominal amnioinfusion is a recently introduced procedure in the field of fetal medicine that can improve oligohydramnios with significantly better neonatal outcomes and prolongation of pregnancy than those with persistant oligohydramnios. ${ }^{3}$ This procedure is carried out under ultrasound guidance. An appropriate amount of $0.9 \%$ normal saline is infused into amniotic cavity under strict aseptic conditions. This procedure has been reported to be a low fetal and maternal risk technique which significantly improves fetal intrauterine stay and survival. ${ }^{4}$ It prolongs latency period and improves neonatal outcomes in preterm pregnancies complicated by oligohydramnios. ${ }^{5}$ The exact incidence of the complications associated with this procedure has not been reported; however, even successful serial amnioinfusion remain associated with procedure-related complications (placental abruption and chorioamnionitis). ${ }^{6}$ No local reference is available in this regard.

Resulting oligohydramnios in case of prolonged rupture of membranes is one of the major concerns in terms of poor neonatal outcomes. Any attempt at improving liquor volume may prove fruitful. The aim of this study was to provide evidence of potential benefits and hazards of transabdominal amnioinfusion as compared with conservative management, for preterm premature rupture of membranes.

\section{MATERIALS AND METHODS}

Women having singleton pregnancies with PPROM at 28 to 32 weeks of gestation were admitted to the high risk antenatal ward of maternal and child health centre, PIMS, Islamabad, from Jan 2008 to Dec 2008. Rupture of membranes was confirmed by a sterile speculum where obvious leakage was noted. Gestational age (confirmed by first trimester scan), 
oligohydramnios (amniotic fluid index $<10$ th centile) with minimum pocket of $2 \mathrm{~cm}$, absence of uterine contractions at the time of admission or within 24 hours of admission, normal anomaly scan of the fetus and no biochemical evidence of chorioamnionitis (C-reactive protein $<6$ ), according to the criteria of Gibbs et al, ${ }^{7}$ were included in the study.

After informed consent, women were randomly assigned into two groups, 24 hours after admission, either those receiving expectant management alone, called the control group (bed rest, intravenous antibiotics and corticosteroid therapy for lung maturations) or those due to receive expectant management with transabdominal amnioinfusion, referred to as the amnioinfusion group.

The amniotic fluid index (AFI) was estimated by four quadrant techniques, ${ }^{8}$ and oligohydramnios was documented when AFI was below 10th centile. ${ }^{9}$ Women of both the groups received bed rest, antibiotic prophylaxis and corticosteroid therapy (betamethasone $12 \mathrm{mg}$ intramuscularly, 12 hours apart in two doses).

Weekly serial amnioinfusion was performed in women if AFI fell below the centile chart. A $20 \mathrm{G}$ spinal needle was inserted transabdominally avoiding the transplacental route, and isotonic sodium chloride solution was infused in the amniotic cavity. An average of 200 to $300 \mathrm{ml}$ was infused, the aim being to restore AFI $\geq 10$ th centile. After the procedure, the AFI was measured again and documented. The AFI was repeated as often as 24 hours or at least once weekly. If the repeated AFI was $<5$ th centile, the same procedure was repeated.

Vigilant maternal and fetal monitoring was carried in both the groups which included daily temperature record of the mother and watchfulness for signs of chorioamnionitis like abdominal tenderness, change in the color of liquor or derangement in the infectious profile (TLC, C-reactive protein). A daily nonstress test was performed in both the groups. Latency period (PPROM-delivery interval) was defined as the period of at least one day between rupture of the membranes and delivery. The indications for cesarean delivery were as follows: labor, the diagnosis of chorioamnionitis and fetal distress (defined as persistent tachycardia with reduced variability; recurrent, late or severe variable decelerations).

The neonatal outcomes were assessed in terms of gestational age at the time of birth, fetal birth weight, the Apgar score of the neonate at 1 minute and then at 5 minutes, neonatal sepsis, neonatal jaundice, respiratory distress syndrome and admission of the neonate to neonatal intensive care unit (ICU). Pulmonary hypoplasia was diagnosed on the basis of strict clinical and radiological criteria. Radiological criteria were as follows: a small, bell-shaped chest with well-aerated lung fields, and an elevated diaphragm up to the seventh rib. ${ }^{10}$ Clinical criteria were as follows: a small chest circumference and severe pulmonary insufficiency necessitating high ventilatory settings, complicated by air leak or pulmonary hypertension. Babies were followed till 28 days of birth and any serious event and cause of mortality was documented.

Student's t-test was used for continuous variables and the chi-square test and relative risk for categorical outcomes.

A two-tailed test $(\mathrm{p}<0.05)$ was considered statistically significant. t-test was applied to compare age, gestational age, latency period, fetal birth weight and Apgar score between the control and amnioinfusion group. Chi-square test was used to compare neonatal ICU admission, respiratory distress syndrome, fetal death and procedure-related complications between both the groups. A p-value of \pm 0.05 was considered statistically significant.

\section{RESULTS}

During the study period of 1 year, 60 women between gestational ages 28 and 32 weeks was initially recruited in the study. Among them, three women went into preterm labor within 24 hours of admission and five women revealed biochemical evidence of chorioamnionitis. Sixty women were finally randomized to either the expectant management group or the amnioinfusion group. The baseline characteristics of both the groups were comparable at the time of admission (Table 1).

The amnioinfusion group had significant prolongation in the latency period as compared to the control group (18.47 \pm 6.69 vs $8.93 \pm 4.74$ days; $\mathrm{p}<0.05)$. As shown in Table 2, majority of the women delivered after 2 weeks of transabdominal amnioinfusion as compared to the control group (70 vs 13.3\%). Gestational age was significantly improved in the amnioinfusion group at the time of birth $(32.4 \pm 1.600$ vs $30.86 \pm 2.30$ weeks; $\mathrm{p}<0.05)$.

The perinatal outcomes were significantly improved in neonates of women who underwent transabdominal amnioinfusion. The mean birth weight of babies was significantly increased in the amnioinfusion group than the control group $(\mathrm{p}=0.019)$. In the amnioinfusion group, two $(6.7 \%)$ babies had normal weight of more than $2500 \mathrm{gm}, 22$ (73.3\%) had low birth weight between 1500 and $2500 \mathrm{gm}$, six (20\%) had very low birth weight between 1000 and 1500 gm and there was no baby born who had extremely low birth weight, i.e. below $1000 \mathrm{gm}$. In the control group, 18 (60\%) babies were low-birth weight, $10(33.3 \%)$ were very low-birth weight and two $(6.7 \%)$ were extremely low-birth weight babies. The babies of women with transabdominal amnioinfusion had better Apgar scores at 1 minute and 5 minutes when compared to the control group ( $\mathrm{p}=0.020$ vs 0.004$)$. There were fewer incidences of respiratory distress syndrome, neonatal 
Table 1: Baseline characteristics of the study population

\begin{tabular}{llll}
\hline Variables & $\begin{array}{l}\text { Amnioinfusion } \\
(N=30)\end{array}$ & $\begin{array}{l}\text { Control } \\
(N=30)\end{array}$ & $p$-value* \\
\hline Age (mean \pm SD) & $28.03 \pm 4.56$ & $26.93 \pm 3.667$ & 0.308 \\
Parity $\mathrm{n}(\%)$ & & & 0.217 \\
Primigravida & $8(26.6)$ & $6(20)$ & $19(63.3)$ \\
Multigravida & $21(70)$ & $5(16.6)$ & 0.211 \\
Grandmultipara & $1(3.3)$ & $5.017 \pm 0.826$ & 0.78 \\
Amniotic fluid index at the time of admission (mean $\pm \mathrm{SD})$ & $5.27 \pm 0.721$ & $9.05 \pm 1.56$ & $<6$ \\
Total leukocyte count (TLC) $\left(10^{9} / \mathrm{l}\right)$ & $9.70 \pm 1.19$ & $<6$ & \\
C-reactive protein $(\mathrm{mg} / \mathrm{l})$ & $<6$ & & \\
\hline
\end{tabular}

${ }^{*} \mathrm{p}$-value $<0.05$ is considered significant; Chi-square test and students t-test were used for categorical and continuous variables respectively

Table 2: PPROM-delivery interval

\begin{tabular}{llll}
\hline & $\begin{array}{l}\text { Amnioinfusion } \\
(N=30)\end{array}$ & $\begin{array}{l}\text { Control } \\
(N=30)\end{array}$ & $p^{- \text {-value }}$ \\
\hline $\begin{array}{l}\text { PPROM } \\
\text { (mean } \pm \text {-delivery interval (days) }\end{array}$ & $18.47 \pm 6.699$ & $8.93 \pm 4.741$ & 0 \\
Delivery between 7 and 14 days, $\mathrm{n}(\%)$ & $9(30)$ & $26(86.7)$ & \\
Delivery after 14 days, $\mathrm{n}(\%)$ & $21(70)$ & $4(13.3)$ & \\
\hline
\end{tabular}

${ }^{*} \mathrm{p}$-value $<0.05$ is considered significant; Chi-square test and student's t-test were used for categorical and continuous variables respectively; \#Preterm premature rupture of membranes

Table 3: Perinatal outcomes

\begin{tabular}{|c|c|c|c|}
\hline & $\begin{array}{l}\text { Amnioinfusion } \\
(N=30)\end{array}$ & $\begin{array}{l}\text { Control } \\
(N=30)\end{array}$ & $p$-value * \\
\hline $\begin{array}{l}\text { Mean birth weight }(\mathrm{gm}) \\
(\text { mean } \pm \mathrm{SD})\end{array}$ & $1896.67 \pm 408.93$ & $1664 \pm 333.4$ & 0.019 \\
\hline \multicolumn{4}{|l|}{ Apgar score at 1 minute $n(\%)$} \\
\hline Normal (7-10) & $5(16.7)$ & $0(0)$ & 0.020 \\
\hline Distress (0-6) & $25(83.3)$ & $30(100)$ & \\
\hline \multicolumn{4}{|l|}{ Apgar score at 5 minutes $n(\%)$} \\
\hline Normal $(7-10)$ & $22(73.3)$ & $11(36.7)$ & 0.004 \\
\hline Distress (0-6) & $8(26.7)$ & $19(63.3)$ & \\
\hline \multicolumn{4}{|l|}{ Neonatal morbidity $n(\%)$} \\
\hline NICU" admission & $9(30)$ & $21(70)$ & 0.001 \\
\hline Respiratory distress syndrome & $7(23.3)$ & $15(50)$ & 0.030 \\
\hline Neonatal sepsis & $4(13.3)$ & $12(40)$ & 0.020 \\
\hline Neonatal jaundice & $9(30)$ & $21(70)$ & 0.001 \\
\hline Compression deformities & $2(6.6)$ & $6(20)$ & 0.127 \\
\hline \multicolumn{4}{|l|}{ Neonatal mortality } \\
\hline Perinatal death & $1(3.3)$ & $7(23.3)$ & 0.023 \\
\hline Antepartum death & 0 & 0 & NA \\
\hline Intrapartum death & $1(3.3)$ & $1(3.3)$ & 1.00 \\
\hline Neonatal death & 0 & $6(20)$ & 0.010 \\
\hline
\end{tabular}

${ }^{*} \mathrm{p}$-value $<0.005$ is considered significant; Chi-square test and student's; t-test were used for categorical and continuous variables respectively; ${ }^{\#}$ Neonatal intensive care unit ${ }^{1}$

sepsis, neonatal jaundice and compression deformities in the amnioinfusion group which resulted in fewer NICU admissions. Overall perinatal mortality was lower in the amnioinfusion group when compared to the control group. There was no antepartum death in both the study groups. There was one intrapartum death in each group while there were six neonatal deaths in the control group, i.e. within 28 days of birth (Table 3). The main reasons were neonatal sepsis and respiratory distress syndrome.
There was no placental abruption or cord accident noted in either group. The incidence of chorioamnionitis was significantly decreased in the amnioinfusion group as compared to the control group (16.6 vs 39.4\%).

\section{DISCUSSION}

Preterm premature rupture of membranes is one of the leading causes of perinatal morbidity and mortality, especially in areas where neonatal intensive units are not well established. 
Oligohydramnios has been attributed for impending onset of preterm labor. An alternative explanation is that microbial invasion of the fetus through the site of rupture leads to systemic inflammatory response with redistribution of fetal blood flow, reduced renal perfusion and subsequent oligohydramnios, resulting in the onset of preterm labor. ${ }^{11}$

Greater residual volume of amniotic fluid is associated with improved perinatal outcomes and the amount of residual amniotic fluid is inversely associated with the risk of shortened latency period, endometritis and nonreassuring fetal testing. ${ }^{12,13}$ As a consequence, women who underwent transabdominal amnioinfusion showed an increase in the amniotic fluid volume, with a corresponding lowered incidence of fetal distress in labor and decreased mortality rate. $^{14}$

In our study, antepartum transabdominal amnioinfusion resulted in significant prolongation of PPROM to delivery interval (media 17 vs 8 days; $\mathrm{p}<0.05$ ) which was comparable to the results of Turhan and Atacan who compared transabdominal amnioinfusion with expectant management in pregnancies complicated with PPROM between 23 and 35 weeks of gestation and found that there was significant prolongation in the latency period in the amnioinfusion group when compared to control group (median 15 vs 8 days; $\mathrm{p}<0.05)$. In their study, the gestational age at admission was earlier in the amnioinfusion group but the diversity disappeared at the time of delivery, demonstrating that transabdominal amnioinfusion had a significant impact in prolongation of latency period. However, in our study, the gestational age at the time of admission was similar in both the groups, and significantly improved at the time of delivery in the amnioinfusion group $(p=0.002)$. Contrary to this, a study by Singla $\mathrm{A}^{15}$ did not report improvement in the latency period.

Neonatal outcomes were significantly improved in the amnioinfusion group when compared to the control group. Locatelli ${ }^{16}$ reported significant improvement in birth weights of babies of mothers undergoing transabdominal amnioinfusion, which was similar to our results (mean 1896 vs $1664 \mathrm{gm} ; \mathrm{p}=0.002$ ). The most likely reason attributed for the improvement in birth weights is the prolongation of the latency period. Neonatal outcome in terms of Apgar score in the intervention group was significantly better at both 1 minute $(p=0.007)$ and 5 minutes $(p=0.012)$, similar with the findings of Gramellini et al, ${ }^{17}$ showing less frequency of Apgar scores of $<7$ at 5 minutes $(p<0.001)$ in the group who received amnioinfusion.

The neonatal survival rate was improved in the amnioinfusion group. There were more take home babies in the amnioinfusion group. Similar improved outcomes were also reported by Locatelli et al, where amnioinfusion was carried out in patients with PPROM at less than 26 weeks of gestation. They had reported favorable perinatal outcomes like improved neonatal survival rate, normal fetal lung development and improved neurological outcomes in women who underwent amnioinfusion as compared to those who had persistent oligohydramnios. This highlights the fact that amnioinfusion at such an early gestational age has a positive impact on fetal outcomes. Perinatal death rate in our study was significantly reduced in women who underwent serial amnioinfusion (3.3 vs 23.3\%; $\mathrm{p}=0.023)$ which is also supported by the work of Ogunyemi ${ }^{18}$ whose perinatal death rate was higher in the control group (33vs $83 \% ; \mathrm{p}=0.036)$.

There was reduced rate of respiratory distress syndrome ( $\mathrm{p}<0.01)$, neonatal sepsis $(\mathrm{p}<0.01)$, jaundice and compression deformities in the amnioinfusion group, resulting in fewer admissions to the NICU. Similar results were reported by Ogunyemi and Lee C Yang. ${ }^{19}$ The probable cause is the high circulating volume of amniotic fluid following amnioinfusion. The major reason attributed to improved perinatal outcomes is the adequate maintenance of amniotic fluid volume with serial amnioinfusion and prolongation of latency period.

No placental abruption or cord accident was noted in our study revealing that it is a safe procedure for both mother and baby which was also reported by AK Das. ${ }^{20}$ Although biochemical evidence of chorioamnionitis was reduced in amnioinfusion group, but the cause of chorioamnionitis whether as a result of ruptured membranes or due to amnioinfusion itself could not be justified.

One of the major limitations of the study was that neurological outcomes of the neonates were not assessed due to the short-term nature of the study. However, this issue is important and should be considered as part and parcel of long-term follow-up. Further, randomized controlled studies are suggested for better authentication of results.

However, with improving neonatal intensive care facilities, further studies may consider the role of transabdominal amnioinfusion in pregnancies even at earlier gestations.

\section{CONCLUSION}

Transabdominal amnioinfusion in the manage-ment of PPROM is a safe and effective treatment modality in prolonging the gestational age and thus reducing the incidence of prematurity. The perinatal outcomes were significantly improved both in terms of improved survival rates and reduced neonatal complications.

In countries like ours, with limited adequate neonatal care facilities, this intervention offers promising outcomes for women belonging to every subset of the community. 


\section{REFERENCES}

1. Tranquilli AL, Giannubilo SR, Bezzeccheri V, Seagnoli C. Transabdominal amnioinfusion in preterm premature rupture of membranes: a randomized controlled trial. BJOG 2005;112:759763.

2. Tahir S, Aleem M, Aziz R. Incidence and outcome of pretermpremature rupture of membranes. Pak J Med Sci 2002;18:26-32.

3. Vergani P, Locatelli A, Verderio M, Assi F. Premature rupture of membranes at $<26$ weeks' gestation: role of amnioinfusion in the management of oligohydramnios. Acta Biomed Ateneo parmense 2004;75 (Suppl) 1:62-66.

4. DeSantis M, Scavo M, Noia G, Masini L, Piersigilli F, Romagnoli $\mathrm{C}$, et al. Transabdominal amnioinfusion treatment of severe oligohydramnios in preterm premature of membranes at less than 26 gestational weeks. Fetal Diagn Ther 2003;18:412-417.

5. Turhan NO, Atacan N. Antepartum prophylactic transabdominal amnioinfusion in preterm pregnancies complicated by oligohydramnios. Int J Gynaecol Obstet 2002;76:15-21.

6. Tan LK, Kumar S, Jolly M, Gleeson C, Johnson P. Test amnioinfusion to determine suitability for derail therapeutic amnioinfusion in midtrimester premature rupture of membranes. Fetal Diagn Ther 2003;18:183-189.

7. Gibbs RS, Blanco JD, St Clair PL, Castaneda YS. Quantitative bacteriology of amniotic fluid from women with clinical intraamniotic infection at term. J Invest Dis 1982;145:1-8.

8. Vermillion ST, Kooba AM, Soper DE. Amniotic fluid index values after preterm premature rupture of the membranes and subsequent perinatal infection. Am J Obstet Gynecol 2000; 183(2):271-276.

9. Moore TR, Cayle JE. The amniotic fluid index in normal human pregnancy. Am J Obstet Gynecol 1990;162:1168-1173.

10. Leonidas JC, Bhan I, Beatty EC. Radiographic chest contour and pulmonary air leaks in oligohydramnios related pulmonary hypoplasia (Potter's syndrome). Invest Radiol 1982;17:6-10
11. Romero R, Gomez R, Ghezzi F, et al. A fetal systemic inflammatory response is followed by the spontaneous onset of preterm parturition. Am J Obstet Gynecol 1998;179:186-193.

12. Shumway JB, Al-Malt A, Amon E, Cohlan B, Amini S, Abboud M. Impact of oligohydramnios on maternal and perinatal outcomes of spontaneous premature rupture of the membranes at 18 to 28 weeks. J Matern Fetal Med 1999;81:20-23.

13. Garzetti GG, Ciavattini A, De Cristofaro F, Marca LA, Arduini D. Prophylactic transabdominal amnioinfusion in oligohydramnios for preterm premature rupture of membranes: increase of amniotic fluid index during latency period. Gynecol Obstet Invest 1997;44:249-254.

14. Park JS, Yoon BH, Romero R, Moon JB, Oh SY, Kim JC. The relationship between oligohydramnios and the onset of preterm labor in preterm premature rupture of membranes. Am J Obstet Gynecol 2001;184:459-462.

15. Singla A, Yadav P, Vaid NB, Suneja A, Faridi MM. Transabdominal amnioinfusion in preterm premature rupture of membranes. Int J Gynaecol Obstet 2010 Mar;108(3):199-202. Epub 2009 Dec 16.

16. Locatelli A, Vergani P, Di Pirro G. Role of amnioinfusion in the management of premature rupture of the membranes at $<26$ weeks' gestation. Am J Obstet Gynecol 2000;183:878.

17. Gramellini D, Fieni S, Piantelli G, Faiola S, Kaihura C, Verrotti C, et al. Amnioinfusion: techniques, indicators and controlled retrospective study of 55 cases. Acta Biomed Ateneo 2000;71:325-329.

18. Ogunyemi D, Thompson W. A case controlled study of serial transabdominal amnioinfusion in the management of second trimester oligohydramnios due to premature rupture of membranes. Eur J Obstet Gynecol 2002;102:167-172.

19. Yang LC, Taylor DR, Kaufman HH, Hume R, Calhoun B. Maternal and fetal outcomes of spontaneous preterm premature rupture of membranes. JAOA 2004;104:537-541.

20. Das AK, Jana N, Dasgupta S, Samanta B. Intrapartum transcervical amnioinfusion for meconium-stained amniotic fluid. Int J Gynaecol Obstet 2007;97:182-186. 